\title{
Borderline Resectable Pancreatic Carcinoma
}

National Cancer Institute

\section{Source}

National Cancer Institute. Borderline Resectable Pancreatic Carcinoma. NCI Thesaurus.

Code C157348.

A pancreatic carcinoma term that refers to a continuum between resectable and locally advanced unresectable disease. 